\title{
Potensi dan Kendala dalam Pengembangan Pantai Kelating sebagai Daya Tarik Wisata di Desa Kelating Kabupaten Tabanan
}

Nina Herlina Br Silalahi a, 1, I Nyoman Sunarta a, 2

1ninabrsilalahi@gmail.com, 2nyoman_sunarta@unud.ac.id

a Program Studi S1 Destinasi Pariwisata, Fakultas Pariwisata,Universitas Udayana, Jl. Dr. R. Goris, Denpasar, Bali 80232 Indonesia

\section{Abstract}

This study is about the potentials and constraints in developing of Kelating Beach as a tourist attraction at Village of Kelating, Tabanan Regency. This study is motivated by there's no serious management for Kelating Beach, although this beach has the great potential to developed. This study is important to know potentials and constraints in developing of Kelating Beach as a tourist attraction at Village of Kelating, Tabanan Regency.

This study using a qualitative approach by data collected by observation,interview, and documentation. Data used in this study is qualitative and quantitative and the data used in this study is derived from the primary and secondary data. Mechanical determination informants using purposive sampling. Analysis of the data used in this study is descriptive qualitative method of analysis.

Based on the results of this study, Kelating Beach has great potentials to developed to be a tourist attraction at Village of Kelating. Physical Potentials of Kelating Beach are the beach view of still natural with black sand, surrounded by hills and crag, there's a bat cave, mini waterfall, there's a temple located in front of the beach the named is Taman AgungTemple. In addition, local communities with art and culture, daily activities or communities attitude of friendly also add value a tourist attraction at Village of Kelating, Tabanan Regency. Constraints in developing of Kelating Beach potentials from aspect: tourism community development, tourism product development and marketing of integrated. But in developing Kelating Beach as a tourist attraction at Village of Kelating, Tabanan Regency has constraints one of which is not yet active tourism management agency optimally .

Keywords: Potential and Constrain, Developing the Tourist Attraction.

\section{PENDAHULUAN}

Kabupaten Tabanan merupakan salah satu kabupaten yang berada di Pulau Bali yang memiliki berbagai macam destinasi wisata, salah satunya adalah Pantai Kelating merupakan daya tarik wisata baru yang menarik minat wisatawan baik wisatawan mancanegara maupun domestik.

Pantai Kelating ini berada di Desa Kelating, Kecamatan Kerambitan, Kabupaten Tabanan dimana pantai ini merupakan pantai yang luas yang diapit oleh dua muara diantaranya di sebelah barat berbatasan dengan muara Yeh Lating dan di sebelah timur berbatasan dengan muara Yeh Abe. Pantai Kelating memiliki pemandangan pantai yang terlihat masih alami disertai tebing batu karang dengan pasir berwarna hitam yang memberikan suasana kehidupan yang tenang.

Potensi Pantai Kelating bukan saja potensi alam melainkan potensi budaya yang dimiliki Desa Kelating. Potensi budaya dan adat istiadat merupakan daya tarik tersendiri yang dapat menarik wisatawan dan sekaligus sebagai faktor pendukung yang akan memperkuat potensi suatu wilayah pengembangan. Meskipun pantai ini memiliki potensi yang sangat besar untuk dapat dikembangkan secara optimal, tetapi hingga saat ini belum ada pengelolaan yang serius terhadap Pantai Kelating, baik oleh Pemerintah, investor maupun masyarakat. Melihat keadaan ini sebenarnya masyarakat Desa Kelating sangat menanti-nantikan Pantai Kelating untuk dikembangkan sebagai daya tarik wisata di daerahnya agar dapat bermanfaat bagi peningkatan ekonomi masyarakat lokal.

Dari alasan inilah memutuskan dalam penelitian ini mengangkat tentang potensi dan kendala dalam pengembangan Pantai Kelating. Penelitian ini bertujuan untuk mengetahui potensi dan kendala apa saja dalam pengembangan Pantai Kelating sebagai daya tarik wisata di Desa Kelating, Kabupaten Tabanan.

\section{TINJAUAN PUSTAKA}

\subsection{Tinjauan Penelitian Sebelumnya}

Dalam penelitian yang dilakukan oleh Swadarma (2003) yang lokasi penelitian di Air Terjun Les, Kabupaten Buleleng. Dari hasil penelitiannya mengemukakan bahwa Air Terjun Les sangat potensial untuk dikembangkan sebagai daya tarik wisata alam. Hal ini didukung oleh adanya beberapa potensi yang dimiliki yaitu potensi fisik yang berupa air 
terjun yang menarik, selain itu juga ada potensi non fisik yang berupa kesenian tradisional.

Hasil dari analisis SWOT yang diimplementasikan ke dalam diagram SWOT menunjukkan hasil bahwa kondisi objek saat ini berada pada kuadran 3 (tiga) yang mendukung turn-around atau disebut juga perubahan haluan dengan peluang dasar yang besar tetapi di pihak lain terdapat kendala atau kelemahan internal dari aspek sumber daya manusia (SDM), sarana pendukung dan dari aspek keindahan alam,kebudayaan serta aksesibitas di Air Terjun Les menunjukkan porsi yang dominan. Upaya yang dilakukan Pemerintah maupun pengelola untuk mengatasi kendala tersebut adalah dengan membuat perencanaan nantinya dapat memajukan Air Terjun Les, adapun langkah-langkah yang dapat dilakukan Pemerintah berupa rencana jangka pendek dan jangka panjang.

Persamaan penelitian ini terletak pada fokus penelitian yaitu sama-sama berfokus pada pengembangan daya tarik wisata, sedangkan perbedaannya diantaranya: lokasi penelitian yaitu penelitian sebelumnya lokusnya di Air Terjun Les sedangkan penelitian ini berlokasi di Pantai Kelating, selanjutnya perbedaan terletak pada waktu penelitian serta teknik analisis data, penelitian sebelumnya menggunakan analisis SWOT sedangkan penelitian ini dengan teknik analisis data deskriptif kualitatif.

Selanjutnya dalam penelitian dari $\mathrm{Ni}$ Luh Kadek Rahma wati,dkk (2013) di Desa Kelating Kabupaten Tabanan yang dari hasil penelitiannya, menunjukkan bahwa di Desa Kelating telah terjadi konversi penggunaan lahan pertanian. Dimana terjadi proses konversi penggunaan lahan pertanian ini terjadi disebabkan didukung oleh pembangunan infrastruktur di bidang pariwisata, pertambahan penduduk serta kepemilikan barang-barang berharga bagi petani sebagai pelaku yang melakukan konversi penggunanaan lahan pertanian.

Lalu dampak yang di timbulkan dari konversi penggunaan lahan pertanian adalah dampak positif dan dampak negatif. Dampak positif bagi kondisi sosial ekonomi dari petani baik berupa penggunaan dari lahan, alasan petani mengubah lahan, pekerjaan, pendidikan dan pendapatan serta kepemilikan barang berharga, sedangkan dampak negatif dari terjadi konversi adalah bagi lahan pertanian yang dimiliki akan semakin menjadi berkurang. Dampak negatif yang ditimbulkan dari perkembangan pariwisata juga terjadi di Kuta Utara dimana perkembangan dari pembangunan akomodasi di Kabupaten Kuta Utara juga telah mengakibatkan berkurangnya sawah. Perkembangan pariwisata tersebut muncul diikuti dengan peningkatan jumlah wisatawan dan fasilitas pendukung pariwisata lainnya, oleh sebab itu, daya dukung air di Kabupaten Kuta Utara sudah mengalami defisit, hal ini artinya kondisi semakin memburuk. Penurunan tingkat air tanah telah mengakibatkan kecenderungan orang untuk memperdalam sumur dan mencari sumbernya ke dalam tanah. Hal ini berarti menunjukkkan bahwa debit air tanah mengalami penurunan karena penggunaan air tanah yang sudah melampui potensinya. (Sunarta, 2014). Persamaan penelitian dari Ni Luh Rahma Wati, dkk adalah memiliki lokus yaitu di Desa Kelating.

\section{Landasan Konsep \\ 3.1 Potensi Wisata}

Menurut Pendit (1999) menjelaskan, potensi wisata merupakan segala sumber daya yang ada ditemui di suatu daerah yang dapat dikembangkan menjadi atraksi wisata, dengan kata lain, potensi wisata adalah segala sumber daya yang dimiliki oleh suatu daerah yang dapat dikembangkan menjadi atraksi wisata yang akan dapat dimanfaatkan untuk kepentingan ekonomi, namun tanpa mengabaikan aspek-aspek lainnya. Dalam penelitian ini, potensi wisata di Desa Kelating yaitu terdiri dari potensi fisik dan non fisik dimana potensi fisik yang dimaksud adalah segala sesuatu yang berwujud sehingga dapat disaksikan langsung sebagai daya tarik wisata, sedangkan potensi non fisik yang dimaksud adalah segala sesuatu yang tidak berwujud namun dapat berpengaruh positif dalam mendukung pengembangan di Pantai Kelating.

\subsection{Pengembangan Pariwisata}

Menurut Yoeti (1993) Pengembangan kepariwisataan meliputi 3 (tiga) hal yaitu:

a. Pembinaan Masyarakat Pariwisata

Dalam rangka pengembangan kepariwisataan, hal yang sangat diperlukan adalah pembinaan masyarakat pariwisata, 
karena penyebab hambatan pengembangan kepariwisataan justru sering muncul dalam masyarakat kepariwisataan itu sendiri. Pembinaan masyarakat pariwisata bisa dilaksanakan melalui dua jalur yaitu formal dan informal. Melalui jalur formal, dapat dilakukan dengan pendidikan kepariwisataan, sedangkan jalur informal seperti mengadakan kursus-kursus bidang kepariwisataan.

b. Pembinaan Produk Pariwisata

Pembinaan produk pariwisata secara berkala dan efektif untuk meningkatkan mutu maupun pelayanan di berbagai unsur-unsur produk wisata. Pembinaan tersebut dapat berupa upaya-upaya yang dapat dilakukan seperti pendidikan dan fasilitas, pengaturan dan pengarahan maupun sosialisasi dari Pemerintah yang akan mendorong peningkatan mutu produk pariwisata.

c. Pemasaran yang Terpadu

Di dalam pengembangan kepariwisataan hal yang paling penting adalah pemasaran terpadu atau mempromosikan untuk menarik minat wisatawan.

Berdasarkan uraian diatas, pengembangan yang dimaksud dalam penelitian ini adalah upaya atau langkah yang dilakukan pihak pengelola untuk membuat potensi Pantai Kelating sebagai daya tarik wisata agar bisa berkembang dengan cara memajukan melalui perbaikan, penataan serta sumber daya manusia di Desa Kelating.

\section{METODE PENELITIAN}

Penelitian ini dilakukan di Desa Kelating Kabupaten Tabanan yaitu Pantai Kelating dimana ruang lingkup yang akan dibahas meliputi: potensi dan kendala dalam pengembangan Pantai Kelating sebagai daya tarik wisata di Desa Kelating. Penelitian ini mengunakan teknik analisa dekskriptif kualitatif dengan didukung data kualitatif berupa potensi alam dan budaya Desa Kelating. Adapun teknik penentuan informan menggunakan teknik purposive. Teknik pengumpulan data melalui: observasi ke lokasi penelitian, selain itu melakukan wawancara secara mendalam terhadap Perbekel Desa Kelating dan Ketua Badan Pengelola Pariwisata serta studi kepustakaan.

\section{HASIL DAN PEMBAHASAN}

Pantai Kelating berada tepatnya di banjar dukuh di Desa Kelating yang mata pencaharian mayoritas masyarakatnya sebagai petani. Pantai Kelating dapat dikembangkan sebagai daya tarik wisata yang memiliki berbagai potensi sebagai berikut :

\section{a. Potensi Fisik Pantai Kelating}

1) Pemandangan pantai yang indah, masih alami dengan pasir berwarna hitam yang memberikan suasana tenang nan nyaman karena lokasi pantai ini yang berada jauh dari keramaian dari kota.

2) Pantai Kelating berlokasi dekat dengan daerah pedesaan dan persawahan karena sebelum menuju ke Pantai Kelating ini, perjalanan yang akan ditempuh yaitu melalui daerah pedesaan dan areal persawahan milik masyarakat sekitar. Terdapatnya areal persawahan ini di Pantai Kelating menjadi suatu daya tarik wisata yang dapat dikembangkan untuk wisata pedesaan dengan kegiatan berupa village tracking, cycling, belajar bertani kepada masyarakat lokal sehingga hal ini dapat dijadikan interaksi langsung dengan masyarakat lokal dan dapat menambah variasi kegiatan wisata di Pantai Kelating.

3) Pantai Kelating terlihat masih asri dan alaami karena disekitar pantai ini banyak terdapat bukit dan tebing batu karang.

4) Air terjun mini terdapat di Pantai Kelating yang merupakan daya tarik wisata yang unik bagi Pantai Kelating.

5) Di Pantai Kelating ini juga memiliki ciri khas yang jarang ada di pantai lainnya yaitu terdapat gua kelelawar. Di langit-langit dalam gua, banyak kelelawar terlihat bergelantungan.

6) Pantai Kelating memiliki pura yang berada tepatnya persis menghadap ke pantai yang bernama Pura Taman Agung.

7) Pantai Kelating dikenal juga sebagai lokasi memancing yang sangat strategis bagi yang gemar memancing.

8) Di Pantai Kelating terlihat pangkalan perahu tradisional milik masyarakat nelayan setempat.

\section{b. Potensi Non Fisik Pantai Kelating}

1. Kesenian budaya

Di Desa Kelating memiliki kesenian diantaranya wayang wong merupakan pertunjukkan cerita wayang yang dimainkan oleh sejumlah orang sebagai tokohnya, wayang wong di desa ini 
memiliki ciri khas yaitu jumlah pemainnya terdiri dari 24 topeng.

Tarian tradisional tarian andir, tari tektekan, serta geguntungan merupakan seperangkat alat gambelan sebagai pengiring tembang maupun melodrama.

2. Sikap dan kegiatan sehari-hari masyarakat Masyarakat Desa Kelating bersikap ramah dan terbuka menerima siapa saja yang mengunjungi Pantai Kelating serta mendukung pengembangan di daerahnya. Selain bekerja sebagai petani, masyarakat Desa Kelating juga bekerja sebagai nelayan. Kegiatan sehari-hari sebagai petani dan nelayan yang dapat menjadi daya tarik sehingga hal ini dapat menjadi suatu pengalaman bagi wisatawan.

3. Sarana Penunjang

Suatu daya tarik wisata dapat berkembang apabila didukung oleh sarana yang memadai. Hingga saat ini di Pantai Kelating didukung oleh fasilitas berupa akomodasi penginapan, areal parkir, warung makanan maupun minuman.

4. Aksesibilitas

Kondisi jalan sudah dalam kondisi aspal yang baik dan akses menuju Pantai Kelating sangat mudah dilalui baik menggunakan dengan kendaraan roda dua maupun roda empat dengan jarak Pantai Kelating dari pusat Kota Tabanan hanya $12 \mathrm{~km}$ atau sekitar 30 menit perjalananan dan jika dari Kota Denpasar 28 km atau sekitar 1 jam 10 menit.

\section{c. Kendala Pengembangan Potensi Pantai Kelating}

1) Pembinaan Masyarakat Pariwisata

Hal yang sangat penting dilakukan dalam pengembangan pariwisata Pantai Kelating adalah pembinaan masyarakat pariwisata. Upaya yang telah dilaksanakan dalam pembinaan masyarakat yang sadar wisata yang dilakukan oleh Pemerintah Daerah hingga saat ini adalah sosialisasi atau penyuluhan tentang kepariwisataan, pelatihan keterampilan dalam bidang pariwisata salah satunya bahasa asing dimana kemampuan berbahasa asing merupakan difokuskan bagi orang-orang yang terlibat dalam kegiatan kepariwisataan namun hal ini dinilai masih belum optimal.

\section{2) Pembinaan Produk Pariwisata}

Upaya yang telah dilaksanakan dalam membina kepariwisataan di Pantai Kelating dalam pengembangan Pantai Kelating ditunjukkan dengan melakukan hal diantaranya menjaga lingkungan Pantai Kelating agar tetap bersih. Kegiatan yang dilakukan dalam menjaga dan memelihara potensi alam Pantai Kelating agar terlihat bersih maka pihak pengelola dan masyarakat rutin setiap satu kali dalam seminggu melakukan gotong royong untuk membersihkan sekitar Pantai Kelating.

Disamping itu, hal yang sangat penting bagi destinasi wisata adalah menciptakan suasana aman, oleh sebab itu menciptakan keamanan Pantai Kelating merupakan tugas dan kewajiban bersama masyarakat Desa Kelating. Selanjutnya, pengelolaan kontribusi dari berlangsungnya kegiataan kepariwisataan di Pantai Kelating yaitu melalui tiket masuk atau uang parkir maupun biaya sewa yang dikenakan bagi pedagang yang berjualan ini dilakukan oleh Pihak Pengelola namun Badan Pengelola Pariwisata belum berjalan secara optimal.

Upaya yang belum dilaksanakan dalam membina kepariwisataan di Pantai Kelating diantaranya pengembangan potensi daya tarik wisata menjadi atraksi wisata khas bagi Pantai Kelating. Potensi daya tarik wisata tersebut dinilai sebagai daya tarik tersendiri untuk Pantai Kelating yaitu gua kelelawar dan air terjun mini. Namun hingga saat ini, belum ada sosialisasi yang serius yang dilakukan baik dari pihak pengelola maupun Pemerintah untuk keberadaan gua kelelawar maupun air terjun mini yang ada di Pantai Kelating ini. Selanjutnya, program memperluas area parkir di Pantai Kelating yang menjadi program dari pihak pengelola maupun masyarakat namun belum terealisasi sampai saat ini. Perluasan area parkir merupakan hal yang sangat penting dilakukan karena daya tampung tempat parkir dinilai sudah tidak cukup terutama pada saat ada acara melasti di Pantai Kelating. Pelaksanaan memperluas area parkir ini nantinya dilaksanakan setelah jalur air mengalir ke selatan, sehingga akan ada perataan lahan. Selanjutnya, lahan ini lah yang akan nantinya dimanfaatkan untuk perluasaan area parkir dan lahan tersebut juga bertujuan akan dimanfaatkan untuk memperluas tempat yang digunakan untuk kegiatan leisure Pantai Kelating seperti bola voli dan sepak bola. 


\section{3) Pemasaran yang Terpadu}

Kegiatan promosi dan pemasaran pariwisata merupakan hal yang penting dilakukan untuk memperkenalkan lebih luas Pantai Kelating dengan kekhasan yang dimiliki sebagai daya tarik wisata yang bertujuan tidak lain adalah untuk menarik minat wisatawan untuk datang. Namun sampai saat ini masih belum dilakukan hal ini dikarenakan yaitu belum berjalannya badan pengelola pariwisata secara optimal. Sejauh ini kegiatan pemasaran yang terpadu dilakukan dominan oleh pihak swasta atau pihak penginapan yang ada di Pantai Kelating.

\section{SIMPULAN DAN SARAN}

\subsection{Simpulan}

Pantai Kelating memiliki potensi besar untuk dikembangkan menjadi daya tarik wisata di Desa Kelating. Potensi fisik yang dimiliki berupa pemandangan pantai yang indah masih alami dengan pasir berwarna hitam, pantai yang terlihat asri karena disekitar terdapat bukit dan tebing batu karang, di Pantai Kelating ini memiliki ciri khas yang jarang ada di pantai lainnya yaitu terdapat gua kelelawar, keunikan lainnya yaitu terdapat air terjun mini, dan terdapat memiliki pura yang tepatnya berada persis menghadap ke pantai yang bernama Pura Taman Agung. Selain itu ditambah dengan pemandangan persawahan, aktifitas masyarakat nelayan dan aktifitas memancing yang ada di Pantai Kelating. Disamping itu, masyarakat lokal dengan kesenian budaya, kegiatan sehari-hari maupun sikap masyarakat ramah juga menambah nilai daya tarik bagi Pantai Kelating sebagai daya tarik wisata di Desa Kelating Kabupaten Tabanan.

Kendala pengembangan potensi Pantai Kelating di Desa Kelating disimpulkan dari segi: pembinaan masyarakat pariwisata, pembinaan produk pariwisata dan pemasaran yang terpadu yaitu: upaya yang telah dilakukan oleh pihak pengelola diantaranya pembinaan masyarakat sadar wisata, menjaga dan kebersihan pantai, menciptakan dan menjaga keamanan pantai serta pengelolaan kontribusi dari berlangsungnya kegiatan pariwisata di Pantai Kelating. Upaya yang belum dilaksanakan oleh pihak pengelola diantaranya: pengembangan terhadap potensi alam yang dimiliki Pantai Kelating yaitu air terjun mini dan gua kelelawar untuk dikemas serius menjadi atraksi wisata khas dan baru bagi Pantai Kelating. Namun dalam pengembangan Pantai Kelating sebagai daya tarik wisata di Desa Kelating Kabupaten Tabanan memiliki kendala yaitu salah satunya belum berjalannya badan pengelola pariwisata secara optimal.

\subsection{Saran} lain:

Adapun saran yang dapat diberikan antara

1. Meningkatkan peran Pemerintah, pihak akademisi, lembaga swadaya masyarakat, maupun pihak swasta seperti pihak penginapan dengan memberikan penyuluhan atau sosialisasi dalam upaya pengelolaan dan pengembangan Pantai Kelating sebagai daya tarik wisata di Desa Kelating.

2. Diharapkan agar para stakeholders memberi perhatian lebih atas keberadaan potensi unik yaitu gua kelelawar dan air terjun mini yang dimiliki Pantai Kelating.

3. Agar dapat mengenalkan Pantai Kelating secara luas diharapkan membuat website.

\section{DAFTAR PUSTAKA}

Pendit, Nyoman S.1999. Ilmu Pariwisata. Jakarta: Akademis Pariwisata Trisakti

Rahmawati, Ni Luh Kadek, dkk. 2013. Konversi lahan Pertanian Pesisir Desa Kelating, Kerambitan, Kabupaten Tabanan. Undiksha.

Sunarta, I Nyoman, dkk. 2014. Tourism Development Impacts on Water Resources in Northern Kuta District of Badung Bali. Jurnal. Denpasar: Universitas Udayana

Swadarma, I Ketut.2003. Pengembangan Potensi Air Terjun Les Sebagai Objek Wisata Alam di Desa Les Kecamatan Tejakula, Kabupaten Buleleng. Denpasar: Program Studi Pariwisata Universitas Udayana.

Yoeti, Oka A. 1993. Pengantar Ilmu Kepariwisataan. Bandung: Angkasa 